\title{
PERAN KELUARGA DALAM MENERAPKAN NILAI BUDAYA SUKU SASAK DALAM MEMELIHARA LINGKUNGAN
}

\author{
Septi Mulyanti Siregar ${ }^{1}$, Nadiroh $^{1}$ \\ ${ }^{I}$ Universitas Negeri Jakarta, Jl. Rawamangun Muka, Jakarta Timur, Indonesia \\ Email: mulyantisiregar@gmail.com
}

\begin{abstract}
The interaction that arises from the impact of the residence used as a tourist village one of the habits of the community will be affected as the language and behavior of tourists. Cultural values become the guidelines of human life passed down from generation to generation so that the role of heir in this family becomes very important to be applied to the next generation. The purpose of this study to determine the role of families in applying cultural values that exist in the Sasak tribe. This research was conducted in Ende Village, Kecamatan Pujut, Central Lombok. The method of this research is qualitative descriptive, data obtained from observation, interview, documentation and literature review related to research substance. The results of this study provide information that the family tribe Sasak play an active role in presenting cultural values in children from childhood. The local cultural values of the Sasak tribe include the mother educating the girls weave, the father educates the farm boys, the father and mother show by example make us polite clothing in the village that is a sarong for men and women's woven cloth skirt, family religion will decrease to the child, and most of this can be sustained today because of the role of families who continue to apply cultural values from generation to generation. So, to preserve the cultural values of the tribe sasak required the role of the family, especially parents to inherit the habits and behavior in accordance with the norms prevailing in that tribe.
\end{abstract}

Keywords: Role, Family, Culture Value, Sasak Tribe 


\section{PENDAHULUAN}

Indonesia terdiri dari beragam suku yang tersebar di beberapa pulau, ditengah era globalisasi ini westernisasi dianggap salah satu yang memudarkan budaya lokal karena banyak nilai-nilai barat yang didifusikan ke dalam nilai-nilai lokal. Sementara dapat dipahami bahwa nilai budaya sangat bermanfaat bagi pengembangan kepribadian masyarakat yang dijadikan standar bertingkah laku sehingga dapat hidup harmonis. Berdasarkan Data Statistik Dinas Pariwisata Provinsi NTB (Nusa Tenggara Barat) bahwa kunjungan wisatawan mancanegara meningkat di setiap bulannya, misalnya pada Mei 2016 sebanyak 107.957 orang sedangkan pada Juni 2016 meningkat menjadi sebanyak 130.446 orang. Salah satu destinasi favorit selain pantai yaitu Desa Wisata. Jika wisatawan mancanegara berkunjung ke desa wisata maka secara tidak langsung akan terjadi interaksi sehingga akan berpengaruh pada nilainilai masyarakat setempat.
Nilai-nilai yang berkembang di masyarakat ini disebut dengan budaya. Budaya menurut Brown adalah sebuah sistem aturan yang dinamis, eksplisit dan implisit yang dibangun oleh kelompok-kelompok yang menjalin kelangsungan hidup mereka (Kertamuda, 2009). Desa Ende, Kecamatan Pujut, Lombok Tengah adalah salah satu pemukiman yang dihuni oleh suku asli Lombok yaitu suku sasak. Keluarga suku sasak memiliki peran dalam melestarikan budaya lokal atau identitas kebudayaan (cultural identity) dari pengaruh globalisasi melalui komunikasi lisan dan contoh tingkah laku sehari-hari.

Sistem aturan yang dinamis menjadikan budaya suku sasak menyesuaikan aturan dengan perkembangan zaman, seperti peran keluarga suku sasak dahulu menjalankan fungsi agama yang disebut wetu telu ketika sudah tidak relevan maka kepercayaan yang dijalankan sekarang yaitu sholat lima waktu seperti umat islam lainnya. 
Budaya yang terjadi di masyarakat melibatkan sikap, nilai keyakinan, norma dan perilaku yang dianut bersama oleh suatu kelompok tetapi dijaga secara berbeda oleh setiap kelompok, dikomunikasikan lintas generasi, relatif stabil tetapi mempunyai peluang untuk berubah seiring waktu.

Budaya lokal seperti ini dapat dieksplorasi dengan menelusuri proses pembelajaran satu generasi ke generasi berikutnya (Mungmachon, 2012). Proses pembelajaran biasanya dilakukan oleh orang tua kepada anaknya selaku generasinya atau pewarisnya. Pewarisan nilai-nilai budaya terjadi apabila sudah terinternalisasi dalam diri anak, menurut Reber internalisasi nilai adalah menyatunya nilai dalam diri seseorang (Mulyana, 2004). Kemudian juga dijelaskan internalisasi adalah sebuah proses yang dilakukan oleh pihak yang tengah menerima proses sosialisasi (Narwoko, 2006). Jadi nilainilai budaya dapat diwariskan dalam diri anak sedari kecil sehingga akan terekam dengan baik dalam memori anak sampai masa tua.

Berdasarkan latar belakang ini maka penulis tertarik untuk mengetahui peran keluarga suku sasak di desa ende dalam mendidik anak untuk ikut serta dalam melestarikan nilai-nilai budaya lokal yang berkelanjutan dari satu generasi ke generasi selanjutnya pada suku sasak.

Menurut Taylor dalam (Samuel Gunawan, 1999) budaya adalah suatu kebutuhan yang meliputi pengetahuan, kepercayaan, seni, kesusilaan, hukum, adat istiadat, serta kesanggupan dan kebiasaan lainnya yang dipelajari oleh manusia sebagai anggota masyarakat. Kemudian budaya adalah seistem dari pola-pola tingkah laku yang diturnkan secara sosial yang bekerja menghubungkan komunitas manusiadengan lingkungan ekologi. 
Nilai adalah sesuatu yang berharga, bermutu, menunjukkan kualitas dan berguna bagi kehidupan manusia. Sifat-sifat nilai menuru Daroeso dalam (Kalangie, 1994) salah satunya yaitu nilai berfungsi sebagai daya dorong dan manusia adalah pendukung nilai sehingga manusia bertindak berdasar dan didorong oleh nilai yang diyakininya. Dalam filsafat ada yang disebut dengan nilai etika atau moral adalah nilai baik dan buruk. Nilai moral adalah suatu bagian dari nilai yaitu nilai yang menangani kelakuan baik atau buruk manusia dan kebudayaan menurut Melville J. Herskovits salah satu unsurnya yaitu keluarga sebagai pendidik yang utama. Suatu nilai budaya turun menjadi pola tingkah laku yang terikat kepada kelompok-kelompok yang menjadi adat istiadat atau cara kehidupan manusia.

Menurut Poerwadarminta, peranan berasal dari kata peran yaitu pemain sandiwara, kemudian sesuatu yang menjadi bagian atau memegang pimpinan yang utama. Kemudian Menurut Soerjono Soekanto, peran merupakan aspek dinamis kedudukan (status) apabila seseorang melaksanakan hak dan kewajibannya sesuai dengan kedudukannya maka ia menjalankan suatu peranan. Sedangkan Menurut Kamus Besar Bahas Indonesia, peranan mengandung arti tindakan yang dilakukan oleh seseorang dalam suatu peristiwa. Jadi peranana adalah seseorang yang melaksanakan hak dan kewajiban sesuai dengan kedudukannya dalam suatu peristiwa.

Menurut Mattessich dan Hill, Keluarga merupakan suatu kelompok yang berhubungan kekerabatan, tempat tinggal, atau hubungan emosional yang sangat dekat yang memperlihatkan empat hal yaitu interdepensi, memelihara batas-batas yang terseleksi maupun untuk beradaptasi dengan perubahan dan memelihara identitas sepanjang waktu, dan melakukan tugas-tugas keluarga (Puspitawati, 2012). 
Peran individu dalam keluarga didasari oleh harapan dan pola perilaku dari keluarga, kelompok, peran merupakan serangkaian tingkah laku yang diharapkan orang lain terhadap seseorang sesuai dengan kedudukan dalam sistem, dimana dapat dipengaruhi keadaan sosial (Leny, 2010). Kemudian peranan keluarga terdiri dari 1) Peran ayah, yaitu ayah berperan sebagai suami dari istri dan ayah bagi anak-anak, mencari nafkah, pendidik, pelindung dan pemberi rasa aman, kepala keluarga, anggota dan kelompok sosialnya serta anggota masyarakat dan lingkungannya, 2) Peran ibu, yaitu ibu berperan sebagai istri, dan ibu bagi anak-anak, mengurus rumah tangga, pengasuh dan pendidik anak-anaknya, pelindung, anggota kelompok sosialnya, anggota masyarakat dan lingkungannya serta disamping itu dapat berperan sebagai pencari nafkah tambahan bagi keluarganya, dan 3) Peran anak, yaitu melaksanakan peranan psikososial dengan tingkat perkembangannya baik secara fisik, mental dan spiritual (Leny, 2010).

Bentuk keluarga terdiri dari 1) Keluarga Inti (Nuclear Family) yaitu keluarga yang dibentuk karena ikatan perkawinan yang direncanakan yang terdiri dari suami, istri, dan anak-anak, baik karena kelahiran maupun adopsi, 2) Keluarga Asal (Family Of Origin) yaitu suatu unit keluarga tempat asal seseorang dilahirkan, 3) Keluarga Besar (Extended Family) yaitu keluarga inti ditambah keluarga yang lain (karena hubungan darah), misalnya kakek, nenek, bibi, paman, sepupu, 4) Keluarga Berantai (Social Family) yaitu keluarga yang terdiri dari wanita dan pria yang menikah lebih dari satu kali dan merupakan suatu keluarga inti, 5) Keluarga Duda atau Janda yaitu keluarga yang terbentuk karena perceraian dan atau kematian pasangan yang dicintai, 6) Keluarga Komposit (Composite Family) yaitu keluarga dari perkawinan poligami dan hidup Bersama, 7) Keluarga Kohabitasi (Cohabitation) yaitu dua orang yang 
menjadi satu keluarga tanpa individu adalah bertahan terhadap pernikahan, bisa memiliki anaka tau tidak. Di Indonesia bentuk keluarga tidak lazim dan bertentangan dengan budaya timur dan 8) Keluarga Inses (Incest Family) yaitu bentuk keluarga yang tidak lazim, dengan anak perempuan menikah dengan ayah kandungnya, atau ayah kandung menikah dengan anak tirinya (Sudiharto, 2007).

Berdasarkan Peraturan Pemerintah Nomor 21 Tahun 1994 fungsi keluarga yang harus dijalankan yaitu: 1) Fungsi agama, sebagai sarana awal memperkenalkan nilai-nilai religius kepada anggota keluarga baru. Dalam proses sosialisasi ini, interaksi antar anggota keluarga berlangsung secara interns, 2) Fungsi Sosial Budaya, bertujuan untuk memberikan identitas sosial kepada keluarga itu, termasuk anggota keluarga baru karena awalnya budaya diwariskan, 3) Fungsi Cinta Kasih, biasanya dalam keluarga idelanya terdapat "kehangatan", 4) segala gangguan dan ancaman. Dalam hal ini keluarga berperan sebagai benteng terhadap seluruh anggota keluarga dari gangguan fisik maupun psikis, 5) Fungsi Reproduksi, keberlangsungan keluarga dilanjutkan melalui proses regenerative, dalam hal ini keluarga adalah wadah yang sah dalam proses regenerasi, 6) Fungsi Pendidikan, sebagai wadah sosialisasi primer, keluargalah yang mendidik dan menanamkan nilai-nilai dasar. Ketika proses itu berjalan, perlahanlahan institusi lain (sekolah) akan mengambil peran sebagai wadah sosialisasi sekunder, 7) Fungsi Ekonomi, kesejahteraan keluarga akan tercapai dengan baik jika menjalankan fungsi ini karena keluargalah yang memenuhi kebutuhan-kebutuhan sehari-hari anggota keluarganya, 8) Fungsi Lingkungan, erat kaitannya dengan hubungan lingkungan sekitar. Lingkungan yang harmonis merupakan kondisi yang baik bagi anggota keluarga.

Fungsi Perlindungan, sifat dasar 


\section{METODOLOGI}

Penelitian ini dilakukan di Desa Ende, Kecamatan Pujut, Lombok Tengah pada tanggal 26 April 2017. Lokasi ini dipilih karena peneliti melihat keunikan dari peran keluarga suku sasak yang memiliki nilai-nilai budaya khususnya terkait menjalankan fungsi agama dan fungsi reproduksi yang diturunkan ke generasi selanjutnya.

Metode yang digunakan yaitu metode kualitatif. Menurut Lincoln dan Guba dalam Sugiyono (2005) menjelaskan bahwa konsep sampling yang relevan dipergunakan dalam penelitian kualitatif adalah "variation sampling to document unique variations that have emerged in adapting to different condition". Pemilihan informan menggunakan teknik snow ball yang merupakan teknik pengambilan informan bermula pada salah seorang atau beberapa orang yang dapat dijadikan sebagai sumber informasi. Selanjutnya informan diharapkan dapat meberikan informasi dan terkait peran keluarga khususnsya orang tua dalam melestarikan nilai-nilai budaya. Berdasarkan kriteria yang telah ditentukan maka informan dibatasi dengan maksud agar data yang diperoleh lebih terfokus.

Menurut Sugiyono (2012) bahwa pengumpulan data dapat diperolah dari hasil observasi, wawancara, dokumentasi dan gabungan atau triangulasi. Dalam metode penelitian ini instrument adalah peneliti itu sendiri, peneliti melakukan observasi untuk menggali lebih dalam informasi dan mengamati objek-objek yang ingin diketahui. Pengumpulan data melalui wawancara mandalam (independent interview) menggunakan pedoman wawancara kepada segenap informan. Kemudian informasi dilengkapi dengan melakukan penelusuran data sekunder, referensi dan pustaka berkaitan dengan substansi penelitian.

Metode ini berusaha memahami dan menafsirkan makna suatu peristiwa interaksi tingkah laku manusia dalam 
situasi tertentu, saat proses pengumpulan data bila sudah tejadi jenuh atau tidak ada variasi informasi maka tidak perlu melanjutkan mencari informasi. Dalam penelitian kualitatif penentuan jumlah partisipan dapat ditentukan berdasarkan pendapat dari Creswell (1998) bahwa ukuran sampel yang digunakan adalah 5-25 orang. Penelitian ini menggunakan informan sebanyak 6 orang. Berikut ini data informan:

Tabel 1.1

Data Informan Penelitian

\begin{tabular}{|c|c|c|}
\hline $\begin{array}{l}\text { Kode } \\
\text { Informan }\end{array}$ & $\begin{array}{l}\text { Usia } \\
\text { Anak ke-1 } \\
(\mathrm{Jk})\end{array}$ & $\begin{array}{l}\text { Status } \\
\text { dalam } \\
\text { Penelitian }\end{array}$ \\
\hline L1 & $\begin{array}{ll}8 & \text { tahun } \\
\text { (L) } & \end{array}$ & $\begin{array}{l}\text { Informan } \\
\text { Kunci }\end{array}$ \\
\hline $\mathrm{P} 2$ & $\begin{array}{ll}8 & \text { tahun } \\
\text { (P) } & \end{array}$ & $\begin{array}{l}\text { Informan } \\
\text { Utama }\end{array}$ \\
\hline P3 & $\begin{array}{l}17 \text { tahun } \\
\text { (L) }\end{array}$ & $\begin{array}{l}\text { Informan } \\
\text { Utama }\end{array}$ \\
\hline $\mathrm{P} 4$ & $\begin{array}{ll}20 & \text { tahun } \\
\text { (L) } & \end{array}$ & $\begin{array}{l}\text { Informan } \\
\text { Utama }\end{array}$ \\
\hline L5 & $\begin{array}{l}10 \text { tahun } \\
\text { (P) }\end{array}$ & $\begin{array}{l}\text { Informan } \\
\text { Utama }\end{array}$ \\
\hline P6 & 26 tahun & Informan \\
\hline
\end{tabular}

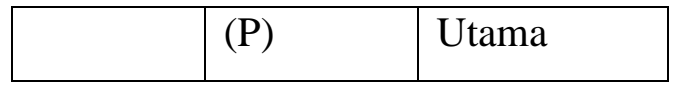

\section{HASIL DAN PEMBAHASAN}

Luas wilayah Desa Ende tidak terlalu luas kira-kira 1 hektar sehingga dapat berkeliling desa dengan berjalan kaki. Desa Ende terdiri dari 30 rumah adat yang disebut dengan bale tani karena profesi sebagian besar masyarakatnya sebagai petani. Kamar mandi di desa ini tidak ada di dalam rumah melainkan kamar mandi yang dipakai secara umum yang ada dibeberapa titik sudut desa. Sumber air yang dipakai untuk kegiatan rumah tangga dari air sumur. Kemudian urusan rumah tangga seperti memasak dilakukan di dalam rumah yang masih memakai kayu bakar. Selain tugas mengurus rumah tangga maka ada fungsi keluarga yang sangat penting dan utama yaitu mendidik anak.

Peran Ibu dalam Menerapkan Nilai Budaya

Berdasarkan wawancara yang peneliti lakukan bahwa keluarga suku sasak 
khususnya ibu atau istri memiliki peran yang dominan dalam menerapkan nilai-nilai budaya pada anak-anaknya. Peran ibu pada suku sasak sudah sesuai dengan teori-teori keluarga yaitu seorang ibu menumbuhkan perasaan sayang, cinta, melalui kasih sayang dan kelembutan sorang ibu, menumbuhkan kemampuan berbahasa dengan baik kepada anak, mengajarkan anak perempuan berperilaku sesuai jenis kelaminnya dengan baik.

Nilai budaya yang diterapkan seorang ibu kepada anaknya bertujuan untuk membentuk tingkah lakunya di masyarakat sehingga sesuai dengan norma yang berlaku. Suku sasak membagi ranah kerja pada anak lakilaki dan perempuan, hal itu sudah dilaksanakan sejak zaman nenek moyangnya. Seorang anak perempuan memiliki kewajiban untuk menenun tentunya benang berasal dari bahanbahan yang alami. Menurut hasil wawancara kepada informan, perempuan suku sasak salah satu syarat untuk menikah yaitu harus bisa menenun, nilai yang menjadi tujuan budaya ini yaitu seorang perempuan harus memilik keterampilan agar sewaktu berumah tangga dapat membantu perekonomian keluarga.

Keterampilan menenun ini diajarkan oleh ibu sejak anak perempuannya dirasa sudah mampu untuk menenun, misalnya salah satu informan sudah mengajarkan anak perempuannya sejak usia 6 tahun. Pembelajaran menenun dapat dilakukan oleh masingmasing keluarga karena alat ini menjadi alat yang wajib dimiliki suku sasak di setiap rumah atau keluarga. Kemudian belajar memasak, anakanak perempuan suku sasak sedari kecil sudah dilibatkan membantu memasak ibu di dapur. Maka suku sasak sudah menjalankan fungsi ekonomi dan peran perempuan dalam pencari nafkah tambahan.

Masyarakat suku sasak, desa ende seluruhnya beragama islam namun 
tidak melaksanakan wetu telu atau sholat tiga waktu. Sholat yang dilakukan juga lima waktu dan ada tradiri mengaji di masjid, namun informan memberikan informasi bahwa karena jarak masjid dengan desa lumayan jauh harus ke jalan raya maka anak-anak biasanya belajar mengaji dengan ibu atau orang tuanya di rumah sehabis sholat maghrib. Kemudian informan menjelaskan bahwa di desa ini akan didirikan masjid. Peran ibu pada suku sasak telah memberikan hak anak untuk mendapat pendidikan dan menjalankan fungsi agama secara baik.

Desa ende ini sangat menyenangkan karena masyarakatnya sangat ramah dan berpakaian sangat khas, setelah melakukan wawancara ternyata hal tersebut merupakan aturan adat yang memiliki nilai budaya bahwa pakaian sopan untuk wanita yaitu kain tenun atau sarung dan perempuan tidak memakai celana dilingkungan desa. Jika memakai perempuan memakai pakaian ketat maka dianggap tidak sopan oleh masyarakat tersebut. Hal tersebut sudah pasti suku sasak telah menjalankan fungsi sosial budaya bahwa kehidupan berbudaya ada aturan yang harus dipatuhi sesuai norma yang berlaku di masayarakatnya.

Peran ibu sebagai pelindung keluarganya juga tercermin dari suatu budaya yang masih ada hingga saat ini yaitu tradiri kawin lari yang artinya seorang laki-laki menculik anak perempuan untuk menikah. Namun ketika seorang ibu mengetahui maka anak perempuannya tidak diizinkan untuk keluar rumah dan akan dijaga di dalam rumah sebagai bukti cinta dan sayang, walaupun pada akhirnya hal tersebut akan tetap terlaksana karena menjalankan fungsi reproduksi. Menikah bertujuan untuk melahirkan generasi suku sasak selanjutnya yang biasanya calonnya merupakan satu desa atau beda desa tetapi sama-sama suku sasak. Tradisi ini masih dianggap wajar oleh suku sasak sebagai ciri khas pernikahan. 
Peran Ayah dalam Menerapkan Nilai

Budaya

Suku sasak memiliki komunikasi patrialisme atau suatu paham dimana keputusan tertinggi adalah seorang ayah atau suami. Seperti masyarakat biasanya bahwa ayah atau suami berkewajiban untuk mencari nafkah, sebagian besar masyarakatnya berprofesi sebagai petani namun ada beberapa juga yang memiliki pekerjaan sambilan sebagai tour guide dan berternak.

Peran ayah di suku sasak dianatarntya menumbuhkan rasa percaya diri, menumbuhkan anak agar mampu berprestasi dan mengajarkan anak untuk tanggung jawab. Seperti yang dilakukan oleh salah satu informan yaitu mengajak anak laki-lakinya ikut ke ladang untuk membiasakan anak sedari kecil untuk mengenal profesi ayahnya agar setalah besar sudah terbiasaya bertani dan membantu pekerjaan ayahnya. Namun suku sasak, desa ende sangat terbuka dengan teknologi yang ada. Informan tidak menginginkan nasib anaknya seperti dirinya sehingga anak laki-lakinya diizinkan untuk memperoleh pendidikan di sekolah. Hal ini menunjukkan bahwa peran mendidik seorang ayah sangat penting untuk keluarga suku sasak.

Sebagai kepada rumah tangga, ayah harus berperan aktif dalam bermasyarakat, misalnya informan menjelaskan adanya paguyuban suku sasak desa ende yang peduli akan wisatawan yang datang ke desa sehingga sukarela menjadi pemandu. Maka seorang ayah pun mengajarkan anak untuk berbahasa dan menjelaskan secara baik agar dapat mencetak generasi yang baik dalam memandu pengunjung. Fungsi mendidik sudah dilakukan oleh ayah pada suku sasak ini yaitu mempersiapkan anak dalam berbahasa atau berkomunikasi dengan baik dengan melibatkan langsung pada kegiatan aktif paguyubannya. 
Seorang informan menyebutkan bahwa ayah pun memiliki tanggung jawab untuk mengajak anak berlatih taritarian khas suku sasak tetapi biasanya anak sudah mulai mandiri belajar karena seringnya melihat ritual dan pertunjukan sehingga anak tertarik sendiri mempelajarinya.

\section{KESIMPULAN}

Penelitian ini menunjukkan bahwa peran keluarga suku sasak khususnya ayah dan ibu memiliki porsi yang seimbang dalam mendidik anak dalam menerapkan nilai-nilai budayanya. Hal ini ditunjukkan dalam hasil wawancara mengenai peran ayah dan ibu dalam menerapkan nilai budaya dilakukan secara turun temurun dari generasi ke generasi yang pembagian perannya cukup adil antara suami dan istri sehingga nilai budayanya dapat terjaga hingga saat ini dan masyarakat tetap hidup harmonis. Suku sasak meyakini bahwa menerapkan nilai budaya seperti memberi pelajaran bahasa sasak, memakai pakaian adat suku sasak dikehidupan sehari-hari, memberi pelajaran menenun mengajak ke sawah atau hutan untuk mempelajari cara bercocok tanam, memberi pelajaran tradisional, dan lainnya dapat menjaga nilai budaya dari arus negatif globalisasi dan westernisasi. Keluarga suku sasak juga sudah menerapkan 8 fungsi keluarga secara baik dengan kesederhanaan yang tercipta di keluarganya.

\section{DAFTAR PUSTAKA}

Anonim. (2017, Juli 5). Dinas Pariwisata Provinsi NTB. Retrieved from Angka Kunjungan Wisatawan ke NTB Triwulan II 2016: disibudpar.ntbprov.go.id

Creswell, J. W. (1998). Qualitative Inquiry and Research Design, Choosing, Among Five Traditions. California: Sage Publication.

Indonesia, K. B. (2003). Edisi Ketiga. Jakarta: Balai Pustaka.

Kalangie, N. (1994). Kebudayaan dan Kesehatan (Pengembangan 
Pelayanan Kesehatan Primer melalui Pendekatan Sosial Budaya). Jakarta: PT. Kesaint Blanc Indah Corp.

Kertamuda, F. E. (2009). Konseling Pernikahan untuk Keluarga Indonesia. Jakarta: Salemba Humanika.

Leny, R. (2012). Keperawatan Keluarga: plus Contoh Askep Keluarga. Yogyakarta: Nuha Medika.

Mulyana, D. (2004). Metodologi Penelitian Kualitatif: Paradigma Baru Ilmu Komunikasi dan Ilmu Sosial Lainnya. Bandung: Remaja Rosdakarya.

Mungmachon, R. (2012). Knowledge and Local Wisdom: Community Treasure. International Journal of Humanities and Social Science, Vol. 2 No. 13.

Narwoko, D. (2006). Sosiologi Teks Pengantar dan Terapan. Jakarta: Kencana Media Group.

Poerwardarminta, W. (1995). Kamus Besar Bahasa Indonesia. Jakarta: PT. Balai Pustaka.

Puspitawati, H. (2012). Gender dan Keluarga: Konsep dan Realita di Indonesia. Bogor: IPB Press.
Soekanto, S. (2002). Teori Peranan. Jakarta: Bumi Aksara.

Sudiharto. (2007). Asuhan Keperawatan Keluarga dengan Pendekatan Keperawatan Transkultural. Jakarta: EGC.

Sugiyono. (2005). Memahami Penelitian Kualitatif. Bandung: Alfabeta.

Sugiyono. (2012). Memahami Penelitian Kualitatif. Bandung: Alfabeta. 